\title{
Soluble fibers from psyllium improve glycemic response and body weight among diabetes type 2 patients (randomized control trial)
}

\author{
Ayman S. Abutair ${ }^{*}$, Ihab A. Naser and Amin T. Hamed
}

\begin{abstract}
Background: Water-soluble dietary fibers intake may help control blood glucose and body weight.

Objective: The objective of the study was to determine whether soluble fiber supplementation from psyllium improves glycemic control indicators and body weight in type 2 diabetic patients.

Method: Forty type 2 diabetes patients, non-smoker, aged $>35$ years were stratified to different strata according to sex, age, body mass index (BMI) and fasting blood sugar level (FBS) and randomly assigned into two groups; The intervention group which consists of 20 participants was on soluble fiber (10.5 g daily), and the control group which consist of 20 participants continued on their regular diet for eight weeks duration.
\end{abstract}

Results: After 8 weeks of intervention, soluble fiber supplementation showed significant reduction in the intervention group in BMI $(p<0.001)$ when compared with the control group. Moreover, water soluble fiber supplementation proven to improve FBS (163 to $119 \mathrm{mg} / \mathrm{dl}$ ), HbA1c (8.5 to $7.5 \%)$, insulin level (27.9 to $19.7 \mu \mathrm{lU} / \mathrm{mL}$ ), C-peptide (5.8 to $3.8 \mathrm{ng} / \mathrm{ml}$ ), HOMA.IR (11.3 to 5.8) and HOMA- $\beta$ \% (103 to $141 \%$ ).

Conclusion: The reduction in glycemic response was enhanced by combining soluble fiber to the normal diet. Consumption of foods containing moderate amounts of these fibers may improve glucose metabolism and lipid profile in type 2 diabetes patients.

Trial registration: Current Controlled Trials PHRC/HC/28/15.

Keywords: Diabetes, Fiber, Fasting blood sugar, Insulin, Body weight

\section{Background}

Diabetes is the fastest growing chronic condition worldwide. According to Centers for Disease Control and Prevention (CDC), $9.3 \%$ of the U.S. population have diabetes [1]. By 2035 the number of adults having diabetes will increase from 387 to 592 million worldwide [2]. It's now well established that diabetes increases the chances for serious complication such as heart diseases and associated mortality [3]. Diet, exercise and behavioral approaches represent the key for management and prevention of diabetes $[4,5]$. More important, consumption

* Correspondence: as.abutair@gmail.com

Department of Clinical Nutrition, Faculty of Pharmacy, Al-Azhar University Gaza, Gaza Strip, Palestine of dietary fibers were inversely related to type 2 diabetes and cardiovascular disease [6]. Researchers stressed that, consumption of more than $26 \mathrm{~g}$ a day had an $18 \%$ lower risk of developing type 2 diabetes than those with the lowest intake [7]. Fiber is commonly classified as soluble, which dissolves in water or insoluble, which doesn't dissolve [8]. The soluble fibers can dissolves in water to form a gel-like material. Soluble fiber is found in oats, peas, beans, apples, citrus fruits, carrots, barley and psyllium [8]. Interestingly, the solubility of soluble fiber refers to its ability to dissolve in water, forming viscous gels, bypasses the digestion of the small intestine [9], and slows absorption and digestion of carbohydrates [10]. Psyllium is a water-soluble fiber derived from the husks of ripe seeds from Plantago ovate [11], that may 
improves glycemic control [12-14], body weight [15] and improve bowel movement [16] in patients with type 2 diabetes. On the other hand, increased consumption of high glycemic index food was associated with insulin resistance and increased prevalence of metabolic syndrome in patients with type 2 diabetes [17]. The purpose of this study was to investigate the beneficial effects of adding soluble fiber to the normal diet for eight weeks of intervention among diabetes type 2 patients.

\section{Methods and material}

\section{Study design and setting}

This study utilized randomized controlled trial design, with newly identified Type 2 diabetes patients (maximum one year) who were on anti-diabetes medication. Aged more than 35 years of old, male and female and who attend private endocrine clinics in the Gaza Strip. Sample size was calculated using two mean formula, which indicated that 18 respondents in each subjects. However, to ensure power to reach desired statistical outcomes and allow for voluntarily withdrawal, number of subjects were increased to 20 in per group. The study included 20 male and 20 female patients. To insure equal distribution of cases, the subjects were stratified according to sex (male/female), age (35-45 years/4550 years $/ 50-55$ years $/ 55-60$ years), BMI (25-29.99/30$34.99 / 35-39.99)$ and fasting glucose level (110-149 mg, $150-200 \mathrm{mg}$ ) into homogeneous strata, then the subjects were allocated randomly in to intervention and control group. The control group consists of 20 participants did not receive any food supplements throughout the intervention period and instead continued with their regular diets. While, the intervention group consists of 20 participants, and received soluble fiber $10.5 \mathrm{~g}$ daily for eight weeks of intervention.

\section{Intervention protocol}

Soluble fiber was provided to the intervention group in this study, whereas the control group remained on their regular diet. Both groups were on their regular diet and lifestyle. The intervention protocol was designed in a way that $7.0 \mathrm{~g}$ of psyllium was given to the intervention group $15 \mathrm{~min}$ before lunch and $3.5 \mathrm{~g}$ of psyllium $15 \mathrm{~min}$ before dinner with $150 \mathrm{ml}$ of water with each dose. To avoid choking while consuming the psyllium supplements. Respondents instructed to consume psyllium with an adequate amount of water (first melt the fiber dose well in $100 \mathrm{ml}$ of water and drink it, then drink additional $50 \mathrm{ml}$ of water). To insure subjects compliance to the intervention program, subjects were contacted by phone 3 times weekly and they were instructed to fill up the compliance checklists to record the daily consumption of the soluble fiber doses, these checklists were collected weekly.

\section{Dietary stabilization phase}

During a dietary stabilization phase, subjects in both groups were instructed to follow a prescribed diet plan for one week for diabetes, to stabilize the serum glucose level ( $\leq 30 \%$ of total energy as fat, $\leq 10 \%$ of energy as saturated fat, and $\geq 55 \%$ of energy as carbohydrate- focused on complex carbohydrate). Dietary stabilization was not the major focus of this intervention and the main goal of dietary instruction was to encourage subjects to maintain their same dietary patterns throughout the stabilization phase. Also, we have prepared a diet program for diabetes patients for one week, and calories was calculated based on body weight for each participant ( $25 \mathrm{Kcal}$ multiplied by body weight $\mathrm{Kg}$ ).

\section{Measurements}

Anthropometric measurements and biochemical indicators were taken at the baseline, and at the end of the trial. Weight was taken in kilograms and grams. Also, respondents were weighted pre and post intervention with same minimal clothing, without shoes or other heavy accessories such as mobile phones and wallets. Heights measurements were taken using calibrated Stadiometer. Respondents stand with bare feet that are kept together and the head was level with a horizontal Frankfurt plane below an imaginary line from the lower border of the eye orbit to the auditory meatus [18]. Heights were measured in centimeters and millimeters. In addition, the commonly accepted BMI ranges are underweight: under 18.5, normal weight: from 18.5 to 24.9 , overweight: from 25 to 29.9 , obese: over 30 . Furthermore, waist circumference was measured at the midpoint between the lower margin of the last palpable rib and the top of the iliac crest, using a stretch resistant tape [19]. According to the WHO, waist circumference more than $102 \mathrm{~cm}$ for adult male and more than $88 \mathrm{~cm}$ for adult non-pregnant female indicate risk for obesity and its health complications risks [19]. Also, hip circumference is measured in a similar manner to waist circumferences, with the tape being passed around the hips at the widest circumference of the buttocks and the tape measure be kept level and parallel to the floor whilst the measurement is made. The average of three measurements was recorded. Waist to hip ratio (WHR) is the ratio of the circumference of the waist to that of the hips. This is calculated as waist measurement divided by hip measurement $(\mathrm{W} / \mathrm{H})$. WHR is used as a measurement of obesity, which in turn is a possible indicator of other more serious health conditions. The WHO states that abdominal obesity is defined as a WHR above 0.90 for males and above 0.85 for females [19]. The Measured biochemical parameters include insulin level, FBS, hemoglobin A1c, C-peptide. HOMA-IR and HOMA-B\% were calculated in order to predict insulin sensitivity and Beta cell function according 
to the following formulas: HOMA-IR = (glucose mg * insulin level $) / 405$, and HOMA-B\% $=\left(360^{*}\right.$ insulin level $) /$ (glucose $\mathrm{mg}-63$ ) [20].

\section{Kits and devices}

The device used for F.B.S. analysis was (Mindry semiauto chemistry, model BA-88A, S.N WR-04002031) and the kit that was used in this device was (Bio MedGlucose L.S, normal level in the plasma $60-110 \mathrm{mg} / \mathrm{dl}$, and sensitivity: $0.4 \mathrm{mg} / \mathrm{dl}$ ). The device used for $\mathrm{HbA} 1 \mathrm{c}$ analysis was (ClOVER A1c analyzer, model IGM-0023, S.N GWLHCLD0056) and the kit used was (CLOVER A1c test cartridge and used with CIOVER A1c analyzer only, less than $7 \%$ is the treatment goal). The device used for insulin and C-peptide analysis was (Mindry micoplate reader, model MR-691A, S.N. 4100566) and the kits used for Insulin was (DRG Insulin ELISA EIA2935, normal value $2-25 \mu \mathrm{IU} / \mathrm{mL}$, sensitivity: $1.76 \mu \mathrm{IU} /$ $\mathrm{mL}$ ) and for C-Peptide was (DRG C-Peptide ELISA EIA1293 , normal value: $0.5-3.2 \mathrm{ng} / \mathrm{ml}$, sensitivity: $0.064 \mathrm{ng} / \mathrm{ml}$ ).

\section{Data analysis}

Following data collection, all data was reviewed before being entered into the study database. Data were entered into an SPSS (Statistical Package for Social Sciences) version 18.0 for Windows. The data treatment involved cleaning and organizing the data for analysis, which included numbering the results, codifying the data, entering the data into the computer, checking the data for accuracy. The data analysis was divided into two steps: descriptive statistics and analysis of variance. The data are presented in tables. The quantitative data are represented in the form of proportions (\%) and of means with standard deviations or medians. All measurements and indicators of the two groups were compared at the baseline, and after eight weeks of intervention to evaluate the impact of the intervention. To compare the changes in the glycemic control indicators and anthropometric measurements one-way repeated measure ANOVA was used. The level of significance was set at 0.05 .

\section{Results}

Out of 40 subjects four respondents withdrew during the study period, and 36 respondents have completed the trial from the beginning to the end of the study successfully. None of the remaining participants were removed from the entire database, and no missing data was observed of all important variables.

\section{Anthropometric characteristics for both groups at baseline level}

Table 1 presents the anthropometric characteristics of the respondents for both groups. The mean weight for respondents was $89 \mathrm{~kg} \mathrm{SD}$ (13.91), the mean height was
Table 1 Anthropometric characteristics of all respondents

\begin{tabular}{lll}
\hline Variables & Total & \\
\cline { 2 - 3 } & $n(\%)$ & Mean (SD) \\
\hline Weight & & $89(13.91)$ \\
Height & & $1.7(0.11)$ \\
BMI & & $31.7(2.71)$ \\
Normal & $0(0.00)$ & \\
Overweight & $11(30.6)$ & \\
Obese & $25(69.4)$ & \\
Waist circumferences & & \\
More than $102 \mathrm{~cm}$ (male) & $17(94.4)$ & \\
Less than $102 \mathrm{~cm}$ (male) & $1(5.30)$ \\
More than $88 \mathrm{~cm}$ (female) & $18(100)$ & \\
Less than $88 \mathrm{~cm}$ (female) & $0(0.00)$ & \\
Hip circumferences & & \\
Waist to Hip Ratio ${ }^{a}$ & & \\
0.95 or less low risk (male) & $4(22.2)$ & \\
$0.96-1.0$ moderate risk (male) & $2(11.1)$ & \\
More than 1.0 high risk (male) & $12(66.7)$ \\
0.80 or less low risk (female) & $0(0.00)$ \\
$0.81-0.85$ Moderate risk (female) & $2(11.1)$ \\
More than 0.85 high risk (female) & $16(88.9)$ \\
\hline
\end{tabular}

a Health Risk Based Solely on waist to hip ratio (WHR) for male (low risk 0.95 or below, moderate risk 0.96-1 and high risk more than 1, and for female (low risk 0.95 or below, moderate risk $0.96-1$ and high risk more than 1

$1.7 \mathrm{~m} \mathrm{SD}(0.11)$ and the mean BMI was $31.7\left(\mathrm{~kg} / \mathrm{m}^{2}\right) \mathrm{SD}$ (2.71), the majority of the respondents $25(69.4 \%)$ were obese and ranged from class I to class II. The mean waist circumferences was $106.8(7.30) \mathrm{cm}$, and the results showed that the majority of male respondents 17 $(94.4 \%)$ waist circumference were more than normal cut of points $102 \mathrm{~cm}$ for adult male. All female respondents waist circumference were more than normal cut of points $88 \mathrm{~cm}$ for adult female. The mean hip circumferences for respondents was $108.8(7.79) \mathrm{cm}$. The WHR mean of all respondents was $0.99(0.09)$.

\section{Changes in the anthropometric measurements}

After 8 weeks of intervention, significant changes were observed in the majority of anthropometric measurements in either group (Table 2). In intervention group, the weight, BMI, waist circumference and hip circumference were significantly decreased (weight $(2.7 \mathrm{~kg}, p<$ $0.001)$, BMI $\left(0.98 \mathrm{~kg} / \mathrm{m}^{2}, p<0.001\right)$, waist circumference $(2.6 \mathrm{~cm}, p<0.001)$, and hip-circumference $(2.5 \mathrm{~cm}, p<$ $0.001)$ ). The WHR shows some reduction about 0.0019 , in which this reduction was not significant. Psyllium supplementation showed significant improvement on anthropometrics as compared with the control group by 
Table 2 Differences in anthropometrics in the control and intervention groups

\begin{tabular}{|c|c|c|c|c|c|}
\hline \multirow[t]{2}{*}{ Variables } & \multicolumn{2}{|c|}{ Control $(n=18)$} & \multicolumn{2}{|c|}{ Intervention $(n=18)$} & \multirow[t]{2}{*}{$P$ value } \\
\hline & Pre & Post & Pre & Post & \\
\hline Weight (kg) & $87.3(13.45)^{b}$ & $88.1(13.379)^{* *}$ & $91.7(14.42)$ & $88.8(14.78)^{* * *}$ & $<0.001$ \\
\hline BMI $\left(\mathrm{kg} / \mathrm{m}^{2}\right)$ & $31.5(2.66)$ & $31.8(2.66)^{* *}$ & $31.8(2.82)$ & $30.9(2.94)^{* * *}$ & $<0.001$ \\
\hline W.C. (cm) & $107.5(7.07)$ & $107.9(6.77)$ & $106.2(7.66)$ & $103.5(7.65)^{* * *}$ & $<0.001$ \\
\hline Hip.C. (cm) & $107.8(7.84)$ & $108.3(7.87)^{*}$ & $109.9(7.82)$ & $107.3(7.96)^{* * *}$ & $<0.001$ \\
\hline WHR & $1.00(0.100)$ & $1.00(0.100)$ & $0.97(0.073)$ & $0.97(0.072)$ & 0.912 \\
\hline
\end{tabular}

${ }^{a}$ Repeated Measure ANOVA between Control and intervention groups

${ }^{\mathrm{b}}$ Mean (Standard Deviation)

The level of significance is $<0.05$

Asterisk = significantly different by paired $t$-test between baseline and 8 th week in the same intervention group, ${ }^{*} p<0.05,{ }^{* *} p<0.01,{ }^{* * *} p<0.001$

repeated test for treatment (time $\mathrm{x}$ treatment interaction).

\section{Glycemic control indicators characteristics for both groups at baseline level}

Table 3 presents the glycemic control characteristics of the respondents for both groups. The mean FBS was $160 \mathrm{mg} / \mathrm{dl}$, and all the respondents were above normal cut off point which is $110 \mathrm{mg} / \mathrm{dl}$. The mean of HbA1c was $8.5(0.654)$ and the majority of respondents 26 (72.2\%) were above normal cut off point which is from 6 to $8 \%$, and the mean insulin level was $24.8 \mu \mathrm{IU} / \mathrm{mL}$, and $50 \%$ of respondents were in normal reference range $(2-25 \mu \mathrm{IU} / \mathrm{mL})$, and $50 \%$ were higher than the normal reference range, In addition, the mean $\mathrm{C}$-peptide level was $5.5 \mathrm{ng} / \mathrm{ml}$, and the majority of respondents 35 (97.2\%) were above the normal reference range which is

Table 3 Glycemic control indicators characteristics of all respondents

\begin{tabular}{|c|c|c|}
\hline Variables & Total & \\
\hline & $n(\%)$ & Mean (SD) \\
\hline Fasting blood sugar & & $160(18.33)$ \\
\hline Normal range & $1(1.7)$ & \\
\hline $110-149$ mg/dl & $14(38.9)$ & \\
\hline 150-200 mg/dl & $22(61.1)$ & \\
\hline $\mathrm{HbA1c}$ & & $8.5(0.654)$ \\
\hline Within normal level \% & $10(27.8)$ & \\
\hline More than $8 \%$ & $26(72.2)$ & \\
\hline Insulin level & & $24.8(5.916)$ \\
\hline Within normal range & $18(50.00)$ & \\
\hline More than 25 & $18(50.00)$ & \\
\hline C-peptide & & $5.5(1.51)$ \\
\hline Within normal range & $1(2.8)$ & \\
\hline More than 5 & $35(97.2)$ & \\
\hline HOMA-IR & & $9.9(2.824)$ \\
\hline HOMA-B\% & & $94.2(24.375)$ \\
\hline
\end{tabular}

0.5-3.2 ng/ml. Moreover, the mean HOMA-IR and HOMA-B\% were 9.9 and 94.2 respectively.

\section{Changes in the glycemic control indicators}

Changes of glycemic control indicators after 8 weeks of intervention are shown in Table 4. In which FBS, HbA1c, insulin level, C-peptide and HOMA.IR. HOMA.B\% were improved significantly in intervention group (43.6 mg/dl $p<0.001,0,9 \% p=0.013,8.3 \mu \mathrm{IU} / \mathrm{mL}$ $p<0.001,2 \mathrm{ng} / \mathrm{ml} p<0.001,5.5 p<0.001$, respectively) after 8 weeks of intervention. As a result, the supplementation of soluble fiber improved the majority of glycemic control indicators significantly in the intervention group as compared with the control group by repeated test for treatment (time $\mathrm{x}$ treatment interaction).

\section{Discussion}

\section{Anthropometric changes}

At base line level, the mean BMI was 31.7 (2.71) (kg/ $\mathrm{m}^{2}$ ), while the majority of the respondents 25 (69.4\%) were obese and ranged from class I to class II. The majority of male respondents 17 (94.4\%) waist circumferences were more than normal cut of points [21], and all of the female respondents 18 (100\%) waist circumferences were more than normal cut of points [21]. This study indicated that, the inclusion of $10.5 \mathrm{~g}$ of psyllium with daily diet decreased (weight (from 91.7 to $88.8 \mathrm{~kg}$, $p<0.001$ ), BMI (from 31.8 to $30.9 \mathrm{~kg} / \mathrm{m}^{2}, p<0.001$ ), waist circumference (from 106.2 to $107.3 \mathrm{~cm}, p<0.001$ ), hip circumference (from 109.9 to $107.3 \mathrm{~cm}, p<0.001$ ). Unfortunately, results showed significant increment in weight, BMI and waist circumference of the respondents in the control group. Our results are consistent with those of pal et al. study in which the body weight and other anthropometric measurements were significantly improved [22]. This changes in anthropometric measurements might be achieved by stimulation of satiety hormones production that's enhancing satiety [23], Another study confirmed that, increase in fiber intake with regular diet has resulted desirable outcomes such as; increased satiety, reduced hunger, decreased energy intake, 
Table 4 Differences in glycemic control indicators in the control and intervention groups

\begin{tabular}{|c|c|c|c|c|c|}
\hline \multirow[t]{2}{*}{ Variables } & \multicolumn{2}{|c|}{ Control $(n=18)$} & \multicolumn{2}{|c|}{ Intervention $(n=18)$} & \multirow[t]{2}{*}{$P$ value } \\
\hline & Pre & Post & Pre & Post & \\
\hline FBS (mg/dl) & $156(18.28)^{b}$ & $151(11.65)$ & $163(18.26)$ & $120(16.48)^{* * *}$ & $<0.001$ \\
\hline HbA1c (\%) & $8.5(0.62)$ & $8.5(0.56)$ & $8.5(0.69)$ & $7.5(0.54)^{* * *}$ & $<0.001$ \\
\hline Insulin ( $(\mu \mid \mathrm{U} / \mathrm{mL}$ ) & $21.8(5.39)$ & $24.9(5.13)^{*}$ & $27.9(4.81)$ & $19.7(2.90)^{* * *}$ & $<0.001$ \\
\hline C-peptide (ng/ml) & $5.2(1.63)$ & $6.3(1.26)^{* * *}$ & $5.8(1.35)$ & $3.8(0.91)^{* * *}$ & $<0.001$ \\
\hline HOMA.IR & $8.5(2.62)$ & $9.3(2.15)$ & $11.3(2.34)$ & $5.8(1.12)^{* * *}$ & $<0.001$ \\
\hline HOMА.В\% & $85.5(21.40)$ & $102.5(21.77)^{*}$ & $102.9(24.59)$ & $140.7(60.89)^{* *}$ & 0.239 \\
\hline
\end{tabular}

${ }^{a}$ Repeated Measure ANOVA between Control and intervention groups

${ }^{b}$ Mean (Standard Deviation)

The level of significance is $<0.05$

Asterisk $=$ significantly different by paired $t$-test between baseline and 8 th week in the same intervention group, ${ }^{*} p<0.05,{ }^{* *} p<0.01,{ }^{* * *} p<0.001$

increase on chewing time and weight loss [24]. Moreover, fiber itself less energy dense if a large volume is consumed. Fiber-rich food is processed more slowly than other food types [25]. Increased consumption of soluble dietary fiber lead to increase the viscosity in the gastrointestinal tract, improving post meal satiety and decreased subsequent hunger [26-28]. More importantly, satiety can be reached by different proposed mechanisms which include; gastric distension [26], slower absorption of macronutrients resulting in a reduction in postprandial glycemia [29], and enhanced effects of hunger-related hormones such as cholecystokinin, glucagon-like peptide-1 and peptide YY [30]. However, not all studies indicated significant effects of dietry fibers in satiety and body weight regulation [24, 27, 31, 32].

\section{Glycemic control indicators changes}

The magnitude of glycemic control indicators reduction seen in this study were seen in other clinical trials. Feinglos et al., in his clinical trial noted that $3.4 \mathrm{~g}$ dose and $6.8 \mathrm{~g}$ dose of psyllium significantly lowered $\mathrm{HbA1c}$ and FBS [33]. Another study concluded that, a psyllium dose of $5.1 \mathrm{~g} /$ day significantly reduced FBS and HbA1c [34]. Likewise, in the current study all glycemic control indicators were significantly improved when these changes compared FBS, HbA1c, insulin and C-peptide $p<0.001, p<0.001, p<0.001, p=0.001$, respectively). Interestingly, these positive results were achieved due to soluble fiber effect in reducing glucose absorption about $12.2 \%$ and as therapeutic agent for other metabolic control [35], while regular intake of soluble fibers, particularly may have a protective role for the presence of metabolic syndrome of patients with type 2 DM [13]. Though, psyllium as an example of viscose functional water soluble fiber which may delay intestinal transit time and leading to feel fullness [36], retarding the entry of glucose into the bloodstream and lessening the postprandial rise in blood sugar [37]. It may lessen insulin requirements [38]. Soluble fiber may produce a slower and longer-lasting release and absorption of macronutrients due to increased intraluminal viscosity $[26,39]$. In the intestine, the gel-like material that formed by soluble fiber traps nutrients inside its gel and slows down considerably while passing through the digestive tract. Inside the gel, nutrients are protected from the action of digestive enzymes and less likely to reach the wall of the intestines for absorption [40]. This lowers the sharp rise of blood sugar after meal, and improves the sensitivity of the cells to the action of insulin [40]. In addition, Water soluble fiber thickens the unstirred water layer covering the surface of the intestines, which make the nutrients more resistant to cross this layer and to diffuse into the body [41]. Also, it has been reported that, soluble fiber decreased postprandial glucose and insulin responses and influenced concomitant gastrointestinal (GI) peptide responses, especially ghrelin and Peptide YY release [39]. Another clinical trial showed that psyllium improve FBS, insulin, HOMA Index, HbA1c significantly [42]. Another randomized crossover study, demonstrated that high intake of dietary fiber, particularly of the soluble type, improves glycemic control, decreases hyperinsulinemia and lowers plasma lipid concentrations in patients with type 2 diabetes [43]. In addition, the use of HOMA for assessment of $\beta$-cell function and insulin sensitivity which can detect the pathophysiology in those with abnormal glucose tolerance, thus HOMA is useful analysis tool of the treatment [44]. Consequently, recent studies among hyperglycemic individuals with no prior diagnosis of diabetes mellitus found to improve insulin sensitivity and other important metabolic controls [45-49]. This is most likely due to the viscosity of soluble fibers inside the gastrointestinal tract [29]. 


\section{Conclusion}

It seems that soluble fiber from psyllium deserves attention as a potential natural dietary supplements for use in nutritional rehabilitation of type 2 diabetic patients, as it is inexpensive and shows positive results within a short span of time.

\section{Abbreviations}

BMl: Body mass index; CDC: Centers for disease control and prevention; FBS: Fasting blood sugar; HbA1c: Hemoglobin A1c; RCT: Randomized control trial; WHO: World Health Organization; WHR: Waist to hip ratio

\section{Acknowledgements}

We are using this opportunity to express our gratitude to all of participants in this study.

\section{Funding}

This study did not receive grant from any institution or organization.

\section{Availability of data and materials}

According to the policy of BMC, we would like to inform you that all the datasets during and/or analysed during the current study available from the corresponding author on reasonable request.

\section{Authors' contributions}

IAN and ATH conceptualized, supervised and lead the study. ASA contributed to the data collection, data entry, data analysis and wrote the manuscript. All authors participated in the review of the manuscripts, read and approved the final manuscript.

\section{Competing interests}

The authors declare that they have no competing interests.

\section{Consent for publication}

Written informed consent for the publication was obtained from the participants.

\section{Ethics approval and consent to participate}

We confirm our responsibility to deliver this study in accordance with AlAzhar University policies and procedures, which include the University's Financial Regulations, Good Research Practice Standards and the Ethics Policy Governing Research Involving Human Participants, Personal Data and Human Tissue, approval from Deanship of the Faculty of Pharmacy, Graduate Studies and Helsinki Committee. In Submitting this research ethics application form, we also confirm that: The form is accurate to the best of our knowledge and belief. There is no potential material interest that may or may appear to impair the independence and objectivity. Subject to the research being approved. We undertake to inform the ethics reviewers of significant changes to the protocol. We are aware of our responsibility to be up to date and comply with the requirements of the law and relevant guidelines relating to security and confidentiality of personal data. Finally, there is no risks on participants health's who were involved in this study.

Received: 5 April 2016 Accepted: 6 October 2016

Published online: 12 October 2016

\section{References}

1. Control CfD, Prevention. National diabetes statistics report: estimates of diabetes and its burden in the United States, 2014. Atlanta: US Department of Health and Human Services; 2014.

2. Guariguata L, Whiting D, Hambleton I, Beagley J, Linnenkamp U, Shaw J. Global estimates of diabetes prevalence for 2013 and projections for 2035. Diabetes Res Clin Pract. 2014;103(2):137-49.

3. Huxley R, Barzi F, Woodward M. Excess risk of fatal coronary heart disease associated with diabetes in men and women: meta-analysis of 37 prospective cohort studies. BMJ.2006;332(7533):73-78.

4. Hordern MD, Dunstan DW, Prins JB, Baker MK, Singh MAF, Coombes JS. Exercise prescription for patients with type 2 diabetes and pre-diabetes: a position statement from Exercise and Sport Science Australia. J Sci Med Sport. 2012;15(1):25-31
5. Balk EM, Earley A, Raman G, Avendano EA, Pittas AG, Remington PL. Combined diet and physical activity promotion programs to prevent type 2 diabetes among persons at increased risk: a systematic review for the Community Preventive Services Task Force. Ann Intern Med. 2014;163(6):437-51.

6. Kaczmarczyk MM, Miller MJ, Freund GG. The health benefits of dietary fiber: beyond the usual suspects of type 2 diabetes mellitus, cardiovascular disease and colon cancer. Metabolism. 2012;61(8):1058-66.

7. Consortium I. Dietary fibre and incidence of type 2 diabetes in eight European countries: the EPIC-InterAct Study and a meta-analysis of prospective studies. Diabetologia. 2015;58(7):1394-408.

8. Slavin J. Dietary fiber: classification, chemical analyses, and food sources. J Am Diet Assoc. 1987;87(9):1164-71.

9. Wong JM, Jenkins DJ. Carbohydrate digestibility and metabolic effects. J Nutr. 2007;137(11):2539S-46S.

10. Riccardi G, Rivellese AA. Effects of dietary fiber and carbohydrate on glucose and lipoprotein metabolism in diabetic patients. Diabetes Care. 1991;14(12):1115-25.

11. Rotblatt M. Herbal medicine: expanded commission E monographs. Annals of internal medicine. 2000;133(6):487.

12. Dall'Alba V, Silva FM, Antonio JP, Steemburgo T, Royer CP, Almeida JC, et al. Improvement of the metabolic syndrome profile by soluble fibre guar gum in patients with type 2 diabetes: a randomised clinical trial. $\mathrm{Br} J$ Nutr. 2013;110(09):1601-10

13. Steemburgo T, Dall'Alba V, Almeida J, Zelmanovitz T, Gross J, De Azevedo M. Intake of soluble fibers has a protective role for the presence of metabolic syndrome in patients with type 2 diabetes. Eur J Clin Nutr. 2009;63(1):127-33.

14. Wolfram T, Ismail-Beigi F. Efficacy of high-fiber diets in the management of type 2 diabetes mellitus. Endocr Pract. 2010;17(1):132-42.

15. Frati-Munari A, Fernandez-Harp J, Becerril M, Chavez-Negrete A, BanalesHam M. Decrease in serum lipids, glycemia and body weight by plantago psyllium in obese and diabetic patients. Arch Invest Med. 1982;14(3):259-68.

16. Singh B. Psyllium as therapeutic and drug delivery agent. Int J Pharm. 2007:334(1):1-14

17. Sacks FM, Appel LJ, Carey VJ. Low vs high glycemic index diet reply. JAMA. 2015:313(13):1372-3

18. Pearson D, Grace C. How to measure height. Weight management. 2012. p. 220-1.

19. WHO. Waist circumference and waist-hip ratio. 2011.

20. Matthews D, Hosker J, Rudenski A, Naylor B, Treacher D, Turner R. Homeostasis model assessment: insulin resistance and cell function from fasting plasma glucose and insulin concentrations in man. Diabetologia. 1985;28(7):412-9.

21. World Health Organization. Obesity: preventing and managing the global epidemic. World Health Organization; 2000.

22. Pal S, Khossousi A, Binns C, Dhaliwal S, Ellis V. The effect of a fibre supplement compared to a healthy diet on body composition, lipids, glucose, insulin and other metabolic syndrome risk factors in overweight and obese individuals. Br J Nutr. 2011;105(01):90-100.

23. Ye Z, Arumugam V, Haugabrooks E, Williamson P, Hendrich S. Soluble dietary fiber (Fibersol-2) decreased hunger and increased satiety hormones in humans when ingested with a meal. Nutr Res. 2015;35(5):393-400.

24. Pereira MA, Ludwig DS. Dietary fiber and body-weight regulation: observations and mechanisms. Pediatr Clin North Am. 2001;48(4):969-80.

25. Stahl A. 11 Plant-food processing: implications for dietary quality. Foraging Farming. 2014;31:171.

26. Dikeman $\mathrm{CL}$, Fahey Jr GC. Viscosity as related to dietary fiber: a review. Crit Rev Food Sci Nutr. 2006;46(8):649-63.

27. Howarth NC, Saltzman E, Roberts SB. Dietary fiber and weight regulation. Nutr Rev. 2001:59(5):129-39.

28. Mattes $\mathrm{RD}$, Rothacker $\mathrm{D}$. Beverage viscosity is inversely related to postprandial hunger in humans. Physiol Behav. 2001;74(4):551-7.

29. Vuksan V, Sievenpiper JL, Owen R, Swilley JA, Spadafora P, Jenkins D, et al. Beneficial effects of viscous dietary fiber from Konjac-mannan in subjects with the insulin resistance syndrome: results of a controlled metabolic trial. Diabetes Care. 2000;23(1):9-14.

30. Hameed S, Dhillo W, Bloom S. Gut hormones and appetite control. Oral Dis. 2009:15(1):18-26.

31. Weickert MO, Spranger J, Holst JJ, Otto B, Koebnick C, Mhlig M, et al. Wheatfibre-induced changes of postprandial peptide $Y Y$ and ghrelin responses are not associated with acute alterations of satiety. Br J Nutr. 2006;96(05):795-8. 
32. Howarth NC, Saltzman E, McCrory MA, Greenberg AS, Dwyer J, Ausman L, et al. Fermentable and nonfermentable fiber supplements did not alter hunger, satiety or body weight in a pilot study of men and women consuming self-selected diets. J Nutr. 2003;133(10):3141-4.

33. Feinglos MN, Gibb RD, Ramsey DL, Surwit RS, McRorie JW. Psyllium improves glycemic control in patients with type-2 diabetes mellitus. Bioact Carbohydr Diet Fibre. 2013;1(2):156-61.

34. Ziai SA, Larijani B, Akhoondzadeh S, Fakhrzadeh H, Dastpak A, Bandarian F, et al. Psyllium decreased serum glucose and glycosylated hemoglobin significantly in diabetic outpatients. J Ethnopharmacol. 2005;102(2):202-7.

35. Sierra M, Garcia J, Fernandez N, Diez M, Calle A. Therapeutic effects of psyllium in type 2 diabetic patients. Eur J Clin Nutr. 2002;56(9):830-42.

36. Bergmann J, Chassany O, Petit A, Triki R, Caulin C, Segrestaa J. Correlation between echographic gastric emptying and appetite: influence of psyllium. Gut. 1992;33(8):1042-3.

37. Braaten J, Scott F, Wood P, Riedel K, Wolynetz M, Brule D, et al. High glucan oat bran and oat gum reduce postprandial blood glucose and insulin in subjects with and without type 2 diabetes. Diabet Med. 1994;11(3):312-8.

38. Anderson JW, Ward K. High-carbohydrate, high-fiber diets for insulin-treated men with diabetes mellitus. Am J Clin Nutr. 1979;32(11):2312-21.

39. Karhunen $L$, Juvonen KR, Flander SM, Liukkonen K-H, Lhteenmki L, Siloaho $\mathrm{M}$, et al. A psyllium fiber-enriched meal strongly attenuates postprandial gastrointestinal peptide release in healthy young adults. J Nutr. 2010;140(4):737-44.

40. Kritchevsky D, Bonfield CT. Dietary fiber in health and disease. Vol. 427. Springer Science \& Business Media. 2012.

41. Guillon F, Champ M. Structural and physical properties of dietary fibres, and consequences of processing on human physiology. Food Res Int. 2000;33(3):233-45.

42. Cicero AG, Derosa G, Bove M, Imola F, Borghi C, Gaddi A. Psyllium improves dyslipidaemia, hyperglycaemia and hypertension, while guar gum reduces body weight more rapidly in patients affected by metabolic syndrome following an AHA Step 2 diet. Mediterr J Nutr Metab. 2010;3(1):47-54.

43. Chandalia M, Garg A, Lutjohann D, von Bergmann K, Grundy SM, Brinkley LJ. Beneficial effects of high dietary fiber intake in patients with type 2 diabetes mellitus. N Engl J Med. 2000;342(19):1392-8.

44. Wallace TM, Levy JC, Matthews DR. Use and abuse of HOMA modeling. Diabetes Care. 2004;27(6):1487-95.

45. Bays H, Frestedt JL, Bell M, Williams C, Kolberg L, Schmelzer W, et al. Reduced viscosity Barley b-Glucan versus placebo: a randomized controlled trial of the effects on insulin sensitivity for individuals at risk for diabetes mellitus. Nutr Metab. 2011;8:58

46. Isken F, Klaus S, Osterhoff M, Pfeiffer AF, Weickert MO. Effects of long-term soluble vs. insoluble dietary fiber intake on high-fat diet-induced obesity in C57BL/6 J mice. J Nutr Biochem. 2010;21(4):278-84.

47. Juntunen KS, Laaksonen DE, Poutanen KS, Niskanen LK, Mykknen HM. Highfiber rye bread and insulin secretion and sensitivity in healthy postmenopausal women. Am J Clin Nutr. 2003;77(2):385-91.

48. Liese AD, Roach AK, Sparks KC, Marquart L, D'Agostino Jr RB, Mayer-Davis EJ. Whole-grain intake and insulin sensitivity: the Insulin Resistance Atherosclerosis Study. Am J Clin Nutr. 2003;78(5):965-71.

49. Rave K, Roggen K, Dellweg S, Heise T. Improvement of insulin resistance after diet with a whole-grain based dietary product: results of a randomized, controlled cross-over study in obese subjects with elevated fasting blood glucose. Br J Nutr. 2007;98(05):929-36.

\section{Submit your next manuscript to BioMed Central and we will help you at every step:}

- We accept pre-submission inquiries

- Our selector tool helps you to find the most relevant journal

- We provide round the clock customer support

- Convenient online submission

- Thorough peer review

- Inclusion in PubMed and all major indexing services

- Maximum visibility for your research

Submit your manuscript at www.biomedcentral.com/submit 